\title{
A quantitative risk assessment model to evaluate effective border control measures for rabies prevention
}

\author{
Hsin-Yi Weng ${ }^{1}$, Pei-I Wu ${ }^{2}$, Ping-Cheng YAng ${ }^{3}$, Yi-Lun TsaI ${ }^{4}$, \\ Chao-Chin CHANG ${ }^{5 *}$ \\ ${ }^{1}$ Department of Pathobiology, College of Veterinary Medicine, University of Illinois at Urbana-Champaign, \\ 2001 S. Lincoln Ave., Urbana, IL 61802, USA \\ ${ }^{2}$ Bureau of Animal and Plant Health Inspection and Quarantine, Council of Agriculture, Executive Yuan, \\ Taiwan, Republic of China \\ ${ }^{3}$ Animal Technology Institute, Taiwan, Republic of China \\ ${ }^{4}$ Graduate Group in Epidemiology, University of California Davis, Davis, CA 95616, USA \\ ${ }^{5}$ Graduate Institute of Microbiology and Public Health, College of Veterinary Medicine, \\ National Chung Hsing University, 250 Kuo Kuang Rd., Taichung 40227, Taiwan, Republic of China
}

(Received 13 May 2009; accepted 12 October 2009)

\begin{abstract}
Border control is the primary method to prevent rabies emergence. This study developed a quantitative risk model incorporating stochastic processes to evaluate whether border control measures could efficiently prevent rabies introduction through importation of cats and dogs using Taiwan as an example. Both legal importation and illegal smuggling were investigated. The impacts of reduced quarantine and/or waiting period on the risk of rabies introduction were also evaluated. The results showed that Taiwan's current animal importation policy could effectively prevent rabies introduction through legal importation of cats and dogs. The median risk of a rabid animal to penetrate current border control measures and enter Taiwan was $5.33 \times 10^{-8}\left(95\right.$ th percentile: $\left.3.20 \times 10^{-7}\right)$. However, illegal smuggling may pose Taiwan to the great risk of rabies emergence. Reduction of quarantine and/or waiting period would affect the risk differently, depending on the applied assumptions, such as increased vaccination coverage, enforced custom checking, and/or change in number of legal importations. Although the changes in the estimated risk under the assumed alternatives were not substantial except for completely abolishing quarantine, the consequences of rabies introduction may yet be considered to be significant in a rabies-free area. Therefore, a comprehensive benefit-cost analysis needs to be conducted before recommending these alternative measures.
\end{abstract}

rabies / importation / risk assessment / quarantine / animal

\section{INTRODUCTION}

Border control is the primary prevention measure to keep a rabies-free region away from rabies emergence. Canine rabies has been eradicated in Taiwan since 1961 because of the efforts on animal quarantine, large-scale vaccination, and stray animal control [24]. However, until now, canine rabies is still considered to be

\footnotetext{
* Corresponding author: changcc@dragon.nchu.edu.tw
}

one of the most important threats to Taiwan. For example, Taiwan is surrounded by rabiesendemic countries, with which frequent commercial and travelling activities occur. Taiwan also has a high free-roaming-cat/dog population density ${ }^{1}$. The vaccination coverage rate in these animals [24] is hard to reach the recommended

\footnotetext{
${ }^{1}$ Fei C.Y., Estimating the size of household dog and stray dog population in Taiwan, Council of Agriculture, Taipei, 2001.
}

This is an Open Access article distributed under the terms of the Creative Commons Attribution-Noncommercial License (http://creativecommons.org/licenses/by-nc/3.0/), which permits unrestricted use, distribution, and reproduction in any noncommercial medium, provided the original work is properly cited. 
threshold (e.g. 70\%) to prevent rabies outbreak if once a rabid animal is introduced to Taiwan [8]. Nevertheless, Taiwan has been able to maintain rabies-free status until now, since the last rabies outbreak during 1948-19612. This success is mainly attributable to Taiwan's isolated geographic barrier, and also to its strict border control on animal importation, which includes a 21-day isolated quarantine period and a minimum of 180-day waiting period in the country of origin.

To prevent rabies introduction through animal importation, the current border control measures implemented by the Taiwanese government require owners of imported companion animals (cats and dogs) from rabies-infected countries to (1) microchip and vaccinate (using inactivated vaccine) the animals against rabies (at the age of $\geq 90$ days old), (2) wait in the country of origin for an additional 180-day to 1 year after the serological test, and (3) provide associated importation documents, including a rabies vaccination certificate and the results of the neutralization antibody titration test for rabies antibody performed at one of the authorized laboratories. After passing the checking at the entry port, the animal is isolated and quarantined for 21 days or longer and is tested for rabies antibody again during the quarantine.

In several rabies-free countries, similar importation policies for companion animals have been challenged mainly because of an increasing awareness of animal welfare concerns related to lengthy isolated quarantine $[9,10,13,19]$. Furthermore, with the development of anti-rabies vaccination for animals [12], the possibility and safety of replacing quarantine with vaccination certification in controlling the emergence of rabies through animal importation are among great debates implicating professionals and government policy makers $[4,7,11,14,26]$. Therefore, the objectives of this study were the following: (1) quantify the risk of rabies introduction

\footnotetext{
${ }^{2}$ Department of Health, Executive Yuan, Taiwan health statistics, Executive Yuan, Taiwan, Taipei, 1963.
}

through animal importation under the current border control measures, (2) identify important determinants of risk of rabies introduction, and (3) compare the risk of rabies introduction through legal importation under current border control policy and under alternative policies.

\section{MATERIALS AND METHODS}

\subsection{Animal importation and rabies introduction}

This study evaluated the risk of rabies introduction into Taiwan through legal and illegal (i.e. smuggling) importations of cats and dogs. All possible pathways for a rabid cat/dog to enter Taiwan are displayed in Figure 1. The risk for a rabid animal entering Taiwan was modeled by two stages. The first stage was to quantify the risk of rabies infection in the countries of origin. This risk was further stratified by whether the animal was infected before or after anti-rabies vaccination. The second stage was to model the risk of a rabies-infected animal to successfully penetrate current or alternative border control by animal importation regulations, port checking, and law enforcement against smuggling. The variables and their assigned probabilities displayed in Figure 1 were according to the implemented rabies prevention measures. For example, the current border control policy requires the owners of imported cats or dogs to provide the results of neutralization antibody titration test for rabies antibody and associated importation documents, which will be examined by Customs officers at the entry port. After passing the port checking, the animals will then undergo a 21day isolated quarantine. Details on the probability and distribution assignments are discussed later.

\subsection{Risk models}

The risk of rabies introduction was quantified using stochastic models with the variables fitted with different distributions. The information used to estimate the model variables included the data from the Bureau of Animal and Plant Health Inspection and Quarantine (BAPHIQ) in Taiwan, literature reviews, world rabies survey by the World Health Organization (WHO), and compilation of expert opinions. The model variables and their information sources and assigned distributions are listed in Table I. The following are detailed descriptions of the model variables. 

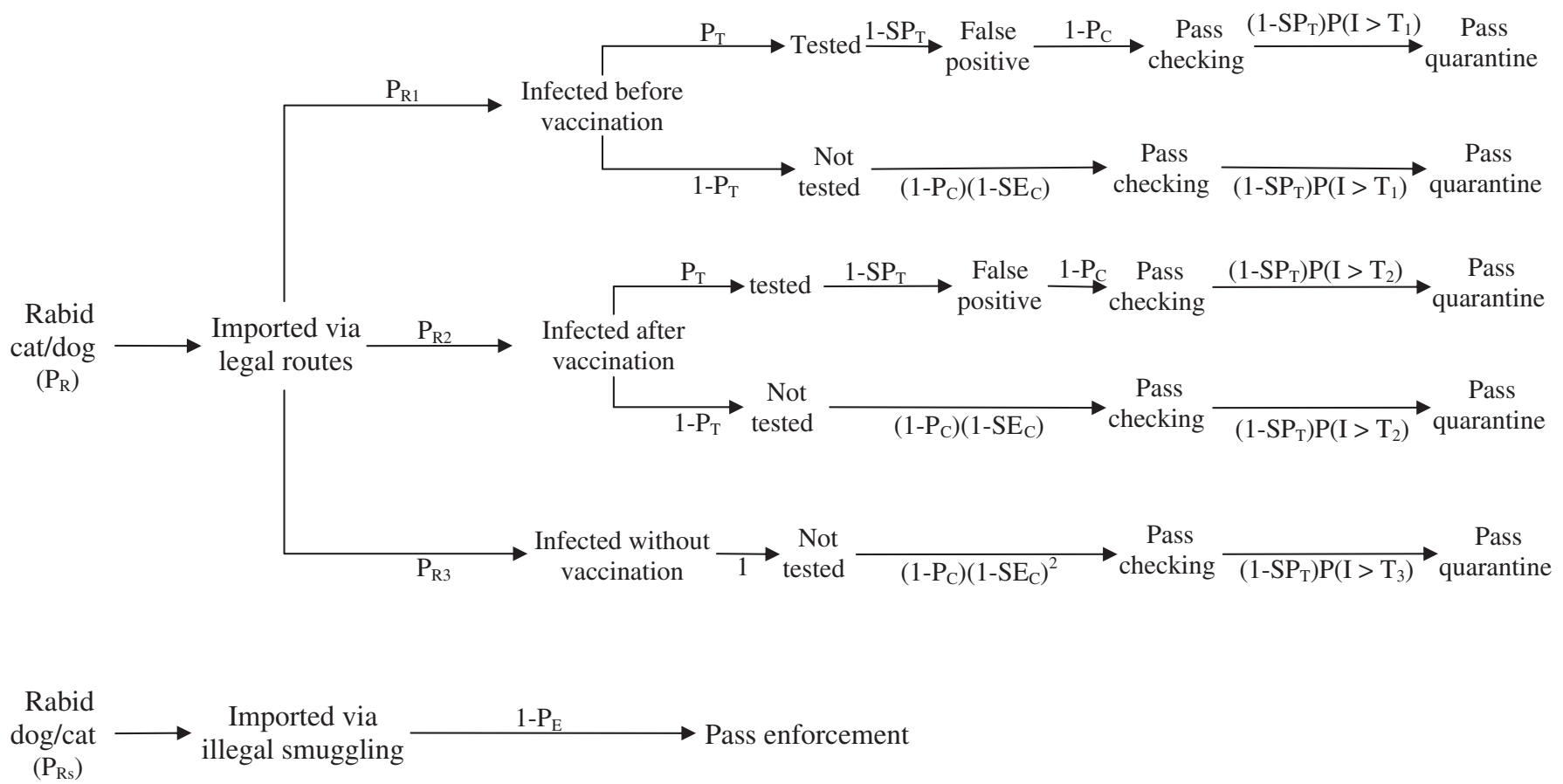

Figure 1. The routes for a rabid dog or cat to enter Taiwan through legal importation or smuggling and the relevant variables and probabilities at each border control step. 
Table I. Model variables, distributions, and information sources.

\begin{tabular}{|c|c|c|}
\hline Model variable & Distribution & Information source \\
\hline $\mathrm{P}_{\mathrm{R}}$ Canada & $\operatorname{Gamma}(1.7,1) / \operatorname{Normal}\left(6.6 \times 10^{6}, 1.68 \times 10^{5}\right)$ & {$[2,3,16-18]$} \\
\hline $\mathrm{P}_{\mathrm{R}}$ Philippine & $\operatorname{Gamma}(331.4,1) / \operatorname{Normal}\left(1.5 \times 10^{6}, 8.0 \times 10^{4}\right)$ & Note $^{3}$ \\
\hline $\mathrm{P}_{\mathrm{R}}$ Thailand & $\operatorname{Gamma}(82.5,1) / \operatorname{Normal}\left(6.1 \times 10^{6}, 4.0 \times 10^{4}\right)$ & Note $^{3}$ \\
\hline $\mathrm{P}_{\mathrm{R}}$ USA & $\operatorname{Gamma}(40.9,1) / \operatorname{Normal}\left(1.34 \times 10^{8}, 9.2 \times 10^{6}\right)$ & {$[2,3,16-18]$} \\
\hline IM Canada & Lognormal $(131.6,17.13)$ & BAPHIQ $^{\mathrm{b}}$ \\
\hline IM Philippine & Exponential(85.2) & BAPHIQ $^{\mathrm{b}}$ \\
\hline IM Thailand & Exponential(287.2) & BAPHIQ $^{b}$ \\
\hline IM USA & Lognormal(371.42, 112.69) & BAPHIQ $^{b}$ \\
\hline $\mathrm{P}_{\mathrm{Rs}}$ & $\operatorname{Beta}(1,149)^{\mathrm{c}}$ & {$[25]$} \\
\hline $\mathrm{VC}$ & Triangle $(0.56,0.89,1)$ & [14] \\
\hline VP & $(\operatorname{Beta}(23,4)+\operatorname{Beta}(27,5)) / 2$ & [1] \\
\hline $\mathrm{PB}$ & Uniform $(0,1)$ & - \\
\hline $\mathrm{P}_{\mathrm{R} 1}$ & $(\mathrm{VC} \times \mathrm{PB}) /$ Total $^{\mathrm{d}}$ & - \\
\hline $\mathrm{P}_{\mathrm{R} 2}$ & $(\mathrm{VC} \times(1-\mathrm{VP}) \times(1-\mathrm{PB})) /$ Total $^{\mathrm{d}}$ & - \\
\hline $\mathrm{P}_{\mathrm{R} 3}$ & $(1-\mathrm{VC}) /$ Total $^{\mathrm{d}}$ & - \\
\hline $\mathrm{P}_{\mathrm{T}}$ & $1-\left(\log -\operatorname{logistic}(0,3.2221,1.2429) / \mathrm{SE}_{\mathrm{C}}\right) / \mathrm{N}^{\mathrm{e}}$ & BAPHIQ $^{\mathrm{b}}$ \\
\hline $\mathrm{SE}_{\mathrm{C}}$ & $\operatorname{Pert}(0.1,0.5,0.9)^{\mathrm{c}}$ & Expert's opinion \\
\hline $\mathrm{SP}_{\mathrm{T}}$ & $\operatorname{Beta}(31,5)$ & {$[6]$} \\
\hline $\mathrm{P}_{\mathrm{C}}$ & Log-logistic $(0,5.2118,3.3618) / \mathrm{N}^{\mathrm{e}}$ & BAPHIQ $^{b}$ \\
\hline I & Log-logistic $(14,39.3,2.02)$ & Note $^{4}$ \\
\hline $\mathrm{P}_{\mathrm{E}}$ & $\operatorname{Pert}(0.01,0.5,0.95)^{\mathrm{c}}$ & Expert's opinion \\
\hline $\mathrm{N}$ & Uniform $(100,3075)^{\mathrm{c}}$ & BAPHIQ ${ }^{\mathrm{b}}$ \\
\hline Ns & Exponential(39) $/ \mathrm{P}_{\mathrm{E}}{ }^{\mathrm{c}}$ & BAPHIQ $^{b}$ \\
\hline
\end{tabular}

${ }^{\text {a }}$ Corresponding publications are listed in the references.

${ }^{\mathrm{b}}$ Data provided by the Bureau of Animal and Plant Health Inspection and Quarantine.

${ }^{c}$ Different values were examined for sensitivity analysis.

${ }^{\mathrm{d}}$ Sum of the numerators of $\mathrm{P}_{\mathrm{R} 1}, \mathrm{P}_{\mathrm{R} 2}$, and $\mathrm{P}_{\mathrm{R} 3}$.

${ }^{\mathrm{e}}$ Truncated to contain the value between 0 and 1 .

\subsubsection{Rabies prevalence in cats and dogs in the exporting country $\left(\boldsymbol{P}_{R}\right)$}

Because the information on rabies incidence and cat/dog population was only available for Canada, the Philippines, Thailand, and the USA, the data from these countries were used to estimate $\mathrm{P}_{\mathrm{R}}$. Based on the 2003-2007 importation records provided by the BAPHIQ, approximately $76 \%$ of cats and dogs were legally imported from these four countries, thus it is reasonable to assume that this estimate is representative of the rabies prevalence in all exporting countries. Rabies prevalence for each of the four countries was calculated by the number of rabies incidence cases modeled using a gamma distribution divided by the cat and dog populations modeled by a normal distribution (Tab. I). The parameter values of the gamma distribution were estimated using the data collected from the WHO world rabies survey ${ }^{3}$ and rabies surveillance in the USA [2, 3, 16-18]. The rabies incubation time of 75 days was used for computation ${ }^{4}$. The cat and dog populations in the USA were estimated from the USA pet ownership and demographic surveys $[5,20,21]$ and USA

\footnotetext{
${ }^{3}$ World Health Organization, WHO Rabies Surveillance and Control - the World Survey of Rabies [online] (2008) http://apps.who.int/globalatlas/ DataQuery/default.asp [consulted 15 August 2008].

${ }^{4}$ World Health Organization, WHO expert consultation on rabies, first report, World Health Organization, Geneva, Switzerland, 2004.
} 
household census ${ }^{5}$. Canada's cat and dog population data were collected from the 2002-2006 rabies surveillance in the USA [2, 3, 16-18]. The dog population data for Thailand and the Philippines were from the WHO world rabies survey ${ }^{3}$ and the paper by Knobel et al. [15], in which the human-to-dog ratio was estimated to be 9.5 in the Philippines. The $P_{R}$ was the average of these four countries weighted by the proportion of companion animals imported from each of the four countries. The distribution of the number imported (IM) for each of the four counties was estimated using the 2003-2007 importation records collected by the BAPHIQ.

\subsubsection{Rabies prevalence among smuggled cats/ $\operatorname{dogs}\left(\boldsymbol{P}_{R S}\right)$}

Despite the difficulty of collecting information on the source of smuggled animals, it is reasonable to assume that the majority of them are from neighboring countries, such as mainland China. In a study, the brain tissue specimens collected from 5 of 283 healthy looking dogs from rural areas in the Guangxi province in China were tested positive for rabies virus [25], indicating that animals smuggled into Taiwan could be coming from an area with very high rabies prevalence. Taiwan currently does not allow animals to be imported from China. Based on the evidence available, a beta distribution assuming that rabies prevalence among smuggled animals could be as high as 0.02 (with a $95 \%$ certainty) and with a mode at the expected value of $P_{R}\left(2.61 \times 10^{-5}\right)$ was fitted to $P_{R s}$. Different values of this variable were further simulated to examine their influence on risk estimation.

\subsubsection{Proportions of a rabid animal contracting the disease before anti-rabies vaccination, after vaccination, and without vaccination $\left(P_{R 1}, P_{R 2}\right.$, and $P_{R 3}$, respectively)}

$\mathrm{P}_{\mathrm{R} 1}, \mathrm{P}_{\mathrm{R} 2}$, and $\mathrm{P}_{\mathrm{R} 3}$ were determined by vaccination coverage (VC), vaccine protection rate (VP), and probability of a vaccinated animal to contact the virus before $(\mathrm{PB})$ or after vaccination (1-PB). The estimate of $\mathrm{VC}$ among imported animals was adopted from the paper by Jones et al. [14]. The anti-rabies vaccine was assumed to have protection only on animals that have not been infected with the disease before vaccination. VP was assigned to a beta distribution with the parameters estimated on the basis of the USA Code of

\footnotetext{
${ }^{5}$ USA Census Bureau, Census 2000 Profile [online] (2002) http://www.census.gov/prod/2002 pubs/c2kprof00-us.pdf [consulted 28 April 2009].
}

Federal Regulations [1], which states that licensed killed rabies vaccines against rabies intended for use in carnivores must protect 22 of 25 or 26 of 30 animals from an intramuscular challenge with a rabies virus for 90 days post challenge and $80 \%$ of controls must die from the challenge. The probability of a vaccinated animal to contact the virus before or after vaccination was assigned to a uniform distribution ranging from 0 to 1 .

\subsubsection{Probability of providing valid documentation of serological test for rabies antibodies $\left(\boldsymbol{P}_{T}\right)$}

The model assumed that the owner who did not have the animal vaccinated would attempt to import the animal with forgery documentation, that is, $\mathrm{P}_{\mathrm{T}}=0$ for the animal. For the animal that was vaccinated, $\mathrm{P}_{\mathrm{T}}$ was estimated using the 2003-2007 records of the BAPHIQ on forgery documentation and was fitted to a log-logistic distribution. $\mathrm{P}_{\mathrm{T}}$ was further adjusted for the probability of successfully identifying forgery documentation through port checking $\left(\mathrm{SE}_{\mathrm{C}}\right)$, which was assumed to follow a pert distribution. Different values for $\mathrm{SE}_{\mathrm{C}}$ were simulated to examine their effects on estimating the risk of rabies introduction.

\subsubsection{Probability for a serological test to successfully identify an animal with insufficient antibody level against rabies $\left(\boldsymbol{S} \boldsymbol{P}_{\boldsymbol{T}}\right)$}

The cutoff used to define insufficient antibody level against rabies was a neutralizing antibody titer of $<0.5 \mathrm{IU} / \mathrm{mL}$ given that the animal was not protected by the vaccine from rabies infection. This probability was assigned to a beta distribution with the parameter values estimated using the results from the study by Cliquet et al. [6].

\subsubsection{Probability of failing port checking other than the reason of providing forgery documentation $\left(\boldsymbol{P}_{C}\right)$}

This variable was estimated by using the 2003 to 2007 animal importation port checking records provided by the BAPHIQ.

\subsubsection{Incubation periods for canine and wildife rabies (I)}

The WHO expert consultation on rabies ${ }^{4}$ states that the incubation period for rabies ranges from 2 
weeks to 6 years with a mean of 2-3 months. This information was used to estimate the parameter values for a log-logistic distribution fitted to this variable.

\subsubsection{Time points at which the animal contracted rabies}

VT: Vaccination time, which was based on the associated regulations and was assigned to a uniform distribution.

$\mathrm{T}_{1}$ : For cats and dogs imported via $\mathrm{P}_{\mathrm{R} 1}$. Assuming that the animal contracted rabies one day before VT in order to maximize the risk.

$\mathrm{T}_{2}$ : For cats and dogs imported via $\mathrm{P}_{\mathrm{R} 2}$. Assuming that the animal contacted the virus anytime between VT and right before entry. Assigned to a uniform distribution ranging from 180 days to 360 days.

$\mathrm{T}_{3}$ : For cats and dogs imported via $\mathrm{P}_{\mathrm{R} 3}$. Assuming that the animal contracted rabies anytime within 6 months before entry.

The time to contracting the disease was crucial in risk computation because it was assumed that a rabid animal only can enter Taiwan if it has yet to show clinical sign before entry. Thus, the probability that an infected animal displayed a clinical sign after entry was dependent on the time between infection and entry, the incubation period, and the waiting period in the exporting country and quarantine and/or monitoring period in the importing country. Under the probability distributions for and these time-related variables, the probability that a rabid animal showed clinical sign after entry was estimated using 100 Latin Hypercube simulations with 1000 iterations each. The mean and standard error derived from the simulations were used in the computation of the associated outcome measures.

\subsubsection{Probabilities of a smuggled rabid cat/dog being enforced by the authority $\left(P_{E}\right)$}

A pert distribution was assigned and different values of the variable were simulated to examine their effects on estimating the risk of rabies introduction.

\subsubsection{Annual number of cats and dogs legally imported to Taiwan (N)}

We used 2003 to 2007 importation records provided by the BAPHIQ to estimate this variable. A uniform distribution was fitted to the variable. Different variable values were simulated to examine their effects on estimating the risk of rabies introduction.

\subsubsection{Annual number of cats and dogs smuggled into Taiwan (Ns)}

Data on smuggling (i.e. including only those having been enforced by patrols) were provided by the BAPHIQ. An exponential distribution was fitted to the variable based on the observed data. The final number of smuggling was adjusted for $\mathrm{P}_{\mathrm{E}}$. Different values for this variable were simulated to examine their influence on risk estimate.

The major assumption of this risk model was that the only possible routes for introducing rabies into Taiwan through animal importation were when a legally imported animal was infected but has yet to display clinical sign before passing all border control measures or when a rabid animal was illegally smuggled into Taiwan without being enforced by patrols. Additional model assumptions were described as follows:

(1) The risk of introducing rabies from rabies free countries was 0 , given the animal did not stop in any rabies-endemic country during the transportation.

(2) The rabies prevalence in legally imported animals was assumed to be the same as the rabies prevalence in their countries of origin.

(3) Probabilities of identifying forgery documentation for vaccination and serological test were the same and independent.

(4) All smuggled animals were assumed to be at risk of being infected with rabies, that is, no vaccination protection among smuggled animals.

(5) Entry of Taiwan was defined as being released from quarantine (including monitoring for wild animals). Thus, it was assumed that a rabid animal would post no risk if it was identified during quarantine or monitoring.

Sensitivity analysis was used to explore important determinants of risk of rabies introduction and to evaluate the influence of the variables that were not supported by sufficient information, including $\mathrm{P}_{\mathrm{Rs}}$, $\mathrm{SE}_{\mathrm{C}}, \mathrm{P}_{\mathrm{E}}$, and Ns, on risk estimate.

\subsection{Outcome measures}

Three outcome measures were used to quantify the risk of introducing rabies into Taiwan through animal importation: (1) the probability for a rabid animal to penetrate rabies prevention measures and enter 
Taiwan $(\phi),(2)$ the annual probability of introducing at least one rabid animal through animal importation $(P)$, and (3) the expected number of years for entry of the first rabies case $(Y)$. The relationship among these three outcome measures were displayed in the following equations (1) and (2):

$$
\begin{gathered}
P=1-(1-\phi)^{k} \\
Y=\frac{1}{\phi k}
\end{gathered}
$$

where $k$ is number of animals imported to Taiwan annually.

Equation (1) assumed that imported animals were independent from each other and that each of them had the same probability of being infected and entering Taiwan. Equation (2) assumed that the assigned probabilities of the model variables were constant across years.

\subsection{Interventions}

Three specific alternative cat/dog importation policies, involving the reduction of the length of quarantine and/or waiting periods, were evaluated in this study. The first intervention was to reduce the length of quarantine period from 21 days to 14, and 7 days, and to abolish isolated quarantine completely (thus also discontinue the second rabies antibody serological test). The second specific intervention was to reduce the minimal waiting time in the country of origin from 180 days to 90,60 , and 21 days. The third intervention was to cross-combine the first two interventions; this is to reduce both quarantine and waiting periods. Four risk models with different assumptions were evaluated. In Model (1), the same assumptions as in the model for the current policy were applied except for changes in quarantine and/or waiting period. Model (2) assumed that the spare resource from the reduction of quarantine period could be used to enhance the port checking $\left(\mathrm{SE}_{\mathrm{C}}\right)$ by $0-10 \%$ (assigned a triangle distribution with a mode at $5 \%$ ) and thus would result in increasing $\mathrm{VC}$ by $0-10 \%$ (using the same Triangle distribution). Model (3) assumed that the alternatives would increase the number of legal importation of cats/dogs by $0-30 \%$ (mode at $15 \%$ ), 0-50\% (mode at 25\%), and 0-100\% (mode at 50\%) for a 14-day (90-day), 7-day (60-day), and 0-day (21-day) quarantine (waiting) period, respectively (all were assigned to triangle distributions). When combing a reduced quarantine period with a reduced waiting period, the changes were assumed to be addictive. For example, annual number of legally imported cats/dogs was assumed to increase by $0-60 \%$ (assigned a triangle distribution with a mode at $30 \%$ ) for a 14-day quarantine combining with a 90-day waiting period. Model (4) used the assumptions made in both Model (2) and Model (3). The annual probability of introducing at least one rabid animal through legal importation of cat/dog $(P)$ estimated by each of the four risk models was compared with the $P$ estimated under the current policy.

\subsection{Simulations}

The models and equations were constructed into Microsoft Excel, and @ Risk 5.0 [22] was used to perform the Latin Hypercube simulations. The models were run for 10000 iterations with a fixed initial seed of 12345 . The median and the 5th and 95th percentiles from the simulation are reported.

\section{RESULTS}

\subsection{Legal importation under current border control policy}

Overall, the risk of a rabid animal to penetrate current border control measures and enter Taiwan (i.e. $\phi$ ) was very low with a median of $5.33 \times 10^{-8}$ and the 95th percentile of $3.20 \times 10^{-7}$ (Tab. II). A non-vaccinated rabid animal contributed most to the risk of rabies introduction (both $\phi$ and $P$ ). A vaccinated animal that contracted the disease after vaccination contributed slightly more to $\phi$ than a vaccinated animal that contracted the disease before vaccination. On the contrary, a vaccinated animal that contracted the disease before vaccination contributed slightly more to $P$ than a vaccinated animal that contracted the disease after vaccination. The median number of years for the first rabies case to enter Taiwan through legal importation of cats and dogs under the current policy was 1822 years with the 5 th percentile of 473 years.

\subsection{Illegal smuggling}

Smuggling placed Taiwan at a great risk of rabies introduction with the median annual probability of 0.098 and the 5 th and 95 th percentiles of 0.003 and 0.737 , respectively. The median number of years for the first rabies case to enter Taiwan through illegal importation of 
Table II. Probability for a rabid cat or dog to penetrate border control measures and enter Taiwan $(\phi)$ and annual probability of introducing at least one rabid animal into Taiwan $(P)$ through legal importation by time to infection.

\begin{tabular}{lccccc}
\hline & \multicolumn{2}{c}{$\phi$} & & $P$ \\
\cline { 2 - 3 } \cline { 5 - 5 } & Median & 5 th, 95th percentiles & & Median & 5th, 95th percentiles \\
\hline $\begin{array}{l}\text { Infected before } \\
\text { vaccination }\end{array}$ & $3.68 \times 10^{-9}$ & $2.89 \times 10^{-10}, 2.59 \times 10^{-8}$ & & $2.64 \times 10^{-6}$ & $5.26 \times 10^{-8}, 3.03 \times 10^{-5}$ \\
$\begin{array}{l}\text { Infected after } \\
\text { vaccination }\end{array}$ & $4.97 \times 10^{-9}$ & $1.81 \times 10^{-10}, 5.93 \times 10^{-8}$ & & $5.43 \times 10^{-7}$ & $1.62 \times 10^{-9}, 2.57 \times 10^{-5}$ \\
$\begin{array}{l}\text { Infected without } \\
\text { vaccination }\end{array}$ & $3.89 \times 10^{-8}$ & $3.79 \times 10^{-9}, 2.63 \times 10^{-7}$ & & $1.33 \times 10^{-5}$ & $4.20 \times 10^{-7}, 1.93 \times 10^{-4}$ \\
Total & $5.33 \times 10^{-8}$ & $6.79 \times 10^{-9}, 3.20 \times 10^{-7}$ & & $6.96 \times 10^{-5}$ & $5.72 \times 10^{-6}, 5.71 \times 10^{-4}$ \\
\hline
\end{tabular}

Table III. Difference $\left(\times 10^{-5}\right)$ in the medain annual probability of introducing at least one rabid cat or dog through legal importation under different reduced quarantine and/or waiting periods, after comparing to the probability under the current policy (i.e. a 21-day quarantine and 180-day waiting periods).

\begin{tabular}{lccccc}
\hline Quarantine period & Model $^{\mathrm{a}}$ & \multicolumn{4}{c}{ Waiting period } \\
\cline { 3 - 5 } & & 21 & 60 & 90 & 180 \\
\hline 0 & Model (1) & 112.61 & 92.37 & 83.61 & 71.19 \\
& Model (2) & 99.23 & 76.41 & 67.77 & 55.63 \\
& Model (3) & 223.49 & 162.52 & 140.28 & 111.29 \\
& Model (4) & 199.41 & 138.19 & 115.24 & 86.40 \\
7 & Model (1) & 6.47 & 4.35 & 3.27 & 1.96 \\
& Model (2) & 5.22 & 2.52 & 1.60 & 0.36 \\
& Model (3) & 15.96 & 9.68 & 7.50 & 4.31 \\
& Model (4) & 13.48 & 7.28 & 5.11 & 1.97 \\
14 & Model (1) & 5.03 & 3.03 & 2.23 & 1.18 \\
& Model (2) & 3.46 & 1.77 & 0.53 & -0.36 \\
& Model (3) & 12.41 & 6.73 & 4.89 & 2.39 \\
& Model (4) & 10.15 & 5.06 & 2.82 & 0.59 \\
& Model (1) & 3.53 & 1.98 & 1.11 & 0 \\
& Model (3) & 8.32 & 3.88 & 2.27 & 0 \\
\hline
\end{tabular}

${ }^{\mathrm{a}}$ Model (1) assumed no other changes except for the quarantine/waiting period; Model (2) assumed an increase in the probability of successfully identifying forgery documentation through port checking and in vaccination coverage; Model (3) assumed an increase in the number of legal importation; and Model (4) included both assumptions of Model (2) and Model (3).

cats and dogs was 9.7 years with the 5th percentile of 9.6 months.

\subsection{Determinates of rabies introduction}

The results indicate that the proportion of animals imported from the Philippines had the strongest (positive) correlation with the risk of a rabid cat/dog to enter Taiwan $(\phi)$, followed by the specificity of the serological test $\left(\mathrm{SP}_{\mathrm{T}}\right)$, and then the probability of identifying forgery documentation $\left(\mathrm{SE}_{\mathrm{C}}\right)$. Both $\mathrm{SP}_{\mathrm{T}}$ and $\mathrm{SE}_{\mathrm{C}}$ had a negative correlation with $\phi$. The results also suggest that the risk of rabies introduction was high through animal smuggling unless it was almost fully controlled. 


\subsection{Interventions}

Table III summarizes the results from the comparison of median annual probability of introducing at least one rabid cat/dog through legal importation (i.e. $P$ ) under each investigated alternative policy and Taiwan's current importation policy using different model assumptions. Model (2), assuming $\mathrm{SE}_{\mathrm{C}}$ and VC would increase by 0 to $10 \%$ if shortening of the quarantine period, generated the smallest change in $P$, while Model (3), assuming that $\mathrm{N}$ would increase if shortening the quarantine and/ or waiting period, generated the largest change in $P$ among the four models. After comparing the risk $\left(6.96 \times 10^{-5}\right)$ under the current policy (180-day waiting period and 21-day quarantine period), the results showed that the complete abolishment of quarantine (and thus also the second serological test for rabies antibody titer) would increase the median $P$ by $5.56 \times 10^{-4}$ to $2.23 \times 10^{-3}$. All the other investigated alternatives changed the median $P$ by $-3.6 \times 10^{-6}$ to $1.60 \times 10^{-4}$.

\section{DISCUSSION}

This study quantitatively evaluated whether different border control measures can effectively prevent the introduction of rabies into a rabies-free area through importation of cats and dogs using Taiwan as an example. The selection of Taiwan as the study site provided several advantages to address the research questions of interest. Taiwan, unlike the regions implicated in previous studies that were conducted in rabies-free areas [7, 14, 19, 23], is located nearby the region with high rabies prevalence, and the risk assessment performed in this study included animal importation from the high risk areas, such as Thailand and the Philippines. Taiwan, however, has similar importation regulations as other rabies-free countries, such as Japan, which make the results from this study generally applicable to these areas.

The study results show that the risk of rabies introduction through legal importation of cats and dogs under Taiwan's current border control policy was pretty low. The true risk is believed to be even lower because we used conservative estimates for the key variables, such as high rabies prevalence in the country of origin $\left(\mathrm{P}_{\mathrm{R}}\right)$ and long rabies incubation period (I), in the models. Further breakdown of the different importation routes revealed that the greatest risk of rabies introduction among legally imported animals was through those who are not vaccinated against rabies. This finding highlights the importance of port checking on forgery documentation, and the additional serological test for rabies antibody titers performed during the quarantine period. The results of sensitivity analysis and investigation of alternative policies further supported this argument. The specificity of the serological test $\left(\mathrm{SP}_{\mathrm{T}}\right)$ and probability of identifying forgery documentation $\left(\mathrm{SE}_{\mathrm{C}}\right)$ were among the most influential determinants of risk estimate and complete abolishment of quarantine (thus also the serological test during quarantine) resulted in a sharp increase in the risk of rabies introduction. In addition, rabies prevalence in the exporting country was identified as one of the most important determinants of rabies introduction into Taiwan through animal importation. Because rabies prevalence varies greatly across countries, a uniform border control policy may not be efficient enough to prevent rabies introduction. Targeting importations from high risk areas by increasing the level of border control measures, for example, more rigorous port checking and/or only allowing animals from these areas with boost vaccination to enter, may be favored. Although complete restriction of importation from high risk areas is another possibility, it may result in an increase in the number of illegal smuggling from these areas and adversely increase the risk of rabies introduction.

Our study demonstrates the importance of controlling illegal smuggling in rabies prevention. With the presumed high rabies prevalence among smuggled animals, our risk model estimated that the risk of rabies introduction could be reduced to an acceptable level only when almost all the smuggled animals were identified and enforced. This finding urges the Taiwanese government and the public to be prepared for the strike of the disease, if smuggling activity 
is not completely prohibited. More efforts on public health education on the risk of rabies introduction through smuggling animals should be considered and applied continuously. Although not investigated in this study, the finding also stresses the importance of the rabies control measures after rabies has emerged, such as increasing public awareness of the disease, vaccination campaign, and stray animal population control, to further protect Taiwan from this fatal disease.

Recently, several studies [7, 11, 14] have been conducted to evaluate the impact of shortening the quarantine time and waiting period on rabies introduction, not only because of the concern for animal welfare but also to encourage people to import animals through legal routes. However, it is important to carefully consider other factors if shortening of these periods is to be directly applied. For example, longer periods will still offer benefits of preventing the imported country from the introduction of other unknown or new emerging infections. The finding that the animals infected after vaccination are more likely to penetrate the control measures than the animals infected before vaccination further reflects the importance of quarantine and waiting periods on identifying rabid animals that have yet displayed clinical signs. Moreover, after shortening these periods, if the number of smuggling still remains the same but the number of legal importation increases, the overall risk of rabies introduction may be increased to an unacceptable level, as previously discussed by Jones et al. [14]. In this study, we not only evaluated the impact of different intervention alternatives on the risk of rabies introduction but also investigated their impacts under different assumptions. As shown in Table III, the increase in risk varied depending on which model assumption was applied. Although our results suggest that most of the increases in the risk of rabies introduction due to the investigated alternatives were not substantial except for the complete abolishment of quarantine, the consequences of rabies introduction may yet be considered to be significant in a rabies-free area.

In conclusion, our study demonstrates that current importation policies for cats and dogs in Taiwan work well on preventing rabies emergence. Port checking, especially targeting importations from high risk areas, is important. Illegal smuggling could be the main concern for rabies introduction. Whether the reduction of quarantine or the waiting period is favorable depends on the applied model assumptions and a comprehensive benefit-cost analysis is essential before recommending these alternative measures.

Acknowledgements. This project was supported by the research grant (97AS-14.6.1-BQ-B2) from the Bureau of Animal and Plant Health Inspection and Quarantine (BAPHIQ), Council of Agriculture, Executive Yuan, Taiwan. The authors greatly appreciate the valuable information provided by the BAPHIQ for this study.

\section{REFERENCES}

[1] Animal and Plant Health Inspection Service, USDA, Code of federal regulations, title 9, part 113.209. Rabies vaccine, killed virus, US Government Printing Office, Washington, DC, 2004.

[2] Blanton J.D., Krebs J.W., Hanlon C.A., Rupprecht C.E., Rabies surveillance in the United States during 2005, J. Am. Vet. Med. Assoc. (2006) 229:1897-1911.

[3] Blanton J.D., Hanlon C.A., Rupprecht C.E., Rabies surveillance in the United States during 2006, J. Am. Vet. Med. Assoc. (2007) 231:540-556.

[4] Briggs D.J., Schweitzer K., Importation of dogs and cats to rabies-free areas of the world, Vet. Clin. North Am. Small Anim. Pract. (2001) 31:573-583.

[5] Center for Information Management, American Veterinary Medical Association, U.S. pet ownership and demographics sourcebook, American Veterinary Medical Association, Schaumburg, IL, USA, 1993.

[6] Cliquet F., Aubert M., Sagne L., Development of a fluorescent antibody virus neutralisation test (FAVN test) for the quantitation of rabies-neutralising antibody, J. Immunol. Methods (1998) 212:79-87.

[7] Cliquet F., Verdier Y., Sagne L., Aubert M., Schereffer J.L., Selve M., et al., Neutralising antibody titration in 25000 sera of dogs and cats vaccinated against rabies in France, in the framework of the new regulations that offer an alternative to quarantine, Rev. Sci. Tech. (2003) 22:857-866.

[8] Coleman P.G., Dye C., Immunization coverage required to prevent outbreaks of dog rabies, Vaccine (1996) 14:185-186. 
[9] Cox M., Barbier E.B., White P.C., Newton-Cross G.A., Kinsella L., Kennedy H.J., Public preferences regarding rabies-prevention policies in the UK, Prev. Vet. Med. (1999) 41:257-270.

[10] Goody S., Welfare of animals in quarantine, Vet. Rec. (1999) 144:456.

[11] Have P., Alban L., Berndtsson L.T., Cliquet F., Hostnik P., Rodeia S.C., Sanaa M., Risk of rabies introduction by non-commercial movement of pets, Dev. Biol. (Basel) (2008) 131:177-185.

[12] Jackson A.C., Wunner W.H., Rabies, 2nd ed., Elsevier/Academic Press, Amsterdam, Boston, 2007.

[13] Jefferies C.C., Replacement of quarantine, Vet. Rec. (1999) 144:623.

[14] Jones R.D., Kelly L., Fooks A.R., Wooldridge M., Quantitative risk assessment of rabies entering Great Britain from North America via cats and dogs, Risk Anal. (2005) 25:533-542.

[15] Knobel D.L., Cleaveland S., Coleman P.G., Fevre E.M., Meltzer M.I., Miranda M.E., et al., Re-evaluating the burden of rabies in Africa and Asia, Bull. World Health Organ. (2005) 83:360-368.

[16] Krebs J.W., Wheeling J.T., Childs J.E., Rabies surveillance in the United States during 2002, J. Am. Vet. Med. Assoc. (2003) 223:1736-1748.

[17] Krebs J.W., Mandel E.J., Swerdlow D.L., Rupprecht C.E., Rabies surveillance in the United States during 2003, J. Am. Vet. Med. Assoc. (2004) 225:1837-1849.
[18] Krebs J.W., Mandel E.J., Swerdlow D.L., Rupprecht C.E., Rabies surveillance in the United States during 2004, J. Am. Vet. Med. Assoc. (2005) 227:1912-1925.

[19] Lopez T., Quarantine changes take effect in Hawaii, J. Am. Vet. Med. Assoc. (1997) 211: 817-819.

[20] Membership \& Field Services, American Veterinary Medical Association, U.S. pet ownership and demographics sourcebook, American Veterinary Medical Association, Schaumburg, IL, USA, 2002.

[21] Membership \& Field Services, American Veterinary Medical Association, U.S. pet ownership \& demographics sourcebook, American Veterinary Medical Association, Schaumburg, IL, USA, 2007.

[22] Palisade Corporation, @RISK for excel, version 5.0, Palisade Corporation, Ithaca, New York, 2007.

[23] Sasaki D.M., Gooch J.M., Cost effectiveness of Hawaii's anti-rabies quarantine program, Hawaii Med. J. (1983) 42:157-160.

[24] Shih Y., Rabies control and prevention in Taiwan, Center for Disease Control, Department of Health, Taipei, 2001.

[25] Tang X., Luo M., Zhang S., Fooks A.R., Hu R., Tu C., Pivotal role of dogs in rabies transmission, China, Emerg. Infect. Dis. (2005) 11:1970-1972.

[26] The Advisory Group on Quarantine, Kennedy review recommends partial replacement of quarantine, Vet. Rec. (1998) 143:374-375. 